\title{
Residentes de pediatria diante da violência doméstica contra crianças e adolescentes ${ }^{*}$
}

Maria Lúcia de Moraes Bourroul ${ }^{1}$

Marina Ferreira Rea

Carlos Botazzo 3

BOURROUL, M.L.M.; REA, M.F.; BOTAZZO, C. Pediatric residents confronted with domestic violence against children and adolescents. Interface - Comunic., Saúde, Educ., v.12, n.27, p.737-48, out./dez. 2008.

This paper sought to understand the perceptions of pediatric residents confronted with domestic violence against children and adolescents (DVCA). A qualitative study was conducted among 67 residents within nine of the 15 programs in the municipality of São Paulo, using semi-structured questionnaires and in-depth interviews with nine subjects. Almost all of the subjects expressed fear and characterized their training as insufficient. The individuals' words suggested discrimination and unfamiliarity towards other people, thus characterizing a situation in which different societies appear threatening. Diagnosing DVCA was the pediatric role most recognized by the interviewees. Although half of them cited notifications, few were doing so through medical reports. There are many points about care for children at risk of violence requiring better understanding. Questions from residents, such as fear, need to be considered so that they are able to recognize such children's characteristics and perform their role better.

Key words: Badly treated children. Medical ethics. Medical education. Medical Residence. Domestic violence.
Buscou-se compreender as percepções de residentes de pediatria diante da violência doméstica contra crianças e adolescentes (VDCA). Realizou-se estudo qualitativo, com 67 residentes, inseridos em nove dos 15 programas existentes no município de São Paulo, com questionários semiestruturados e entrevistas em profundidade com nove sujeitos. A quase totalidade expressou medo e caracterizou a formação como insuficiente. As falas dos sujeitos sugerem discriminação e estranhamento diante do outro, caracterizando situação onde sociedades diferentes aparecem como ameaçadoras. Diagnosticar VDCA foi a atribuição do pediatra mais reconhecida pelos entrevistados; embora metade deles tenha citado a notificação, poucos notificariam com relatório médico. Há etapas do atendimento da criança sob risco de violência a ser mais bem entendidas. Questões do residente, como o medo, devem ser consideradas para que ele possa reconhecer a criança na sua alteridade e desempenhar melhor seu papel.

Palavras-chave: Maus-tratos infantis. Ética médica. Educação médica. Residência médica. Violência doméstica.
"Elaborado a partir de Bourroul (2005). ${ }^{1}$ Médica. Instituto da Criança, Hospital das Clínicas, Faculdade de Medicina, Universidade de São Paulo.

R. Cardeal Arcoverde, 362, casa 3, São Paulo, SP . 05.408-000. malubourroul@terra.com.br ${ }^{2}$ Médica. Instituto de Saúde, Secretaria de Estado da Saúde de São Paulo (IS/SES). ${ }^{3}$ Graduado em Odontologia. IS/SES. 


\section{Introdução}

Violência doméstica contra crianças e adolescentes (VDCA) não é algo novo na experiência humana. Ainda que presente na história de povos e sociedades as mais distintas, na contemporaneidade gera tanto desconforto quanto conformismo. Esta relação ambígua é amplificada pelos meios de comunicação, que veiculam continuamente as suas mais diversas imagens. Nem por isso o entendimento da questão aprofundou-se. Ao contrário, a exposição excessiva termina por naturalizar o fenômeno, visto em geral apenas na perspectiva do indivíduo. No mais, torna a violência cotidiana um fato midiático, o que, sem dúvida, é um poderoso indutor de pânico e desconfiança na sociedade.

Apesar de tais sentimentos serem reais, as suas explicações e as conseqüências que acarretam freqüentemente mantêm-se à tona. Por isso, hoje, mais do que nunca, faz-se necessário sair da superfície e buscar maior compreensão das questões que cercam práticas violentas. Reconhecê-las em sua complexidade, enquanto condição fundadora das relações humanas, histórica e politicamente construída, implica sua desnaturalização, e nesta condição é que podem ser pensadas (Villela, Botazzo, 2004).

Resgatar tais explicações, como algo oculto por debaixo das imagens e impressões imediatas, justo porque aparecem desfocadas nas relações interpessoais ou ocultadas na invisibilidade de instituições e lares, pode, no entanto, gerar sofrimento.

Por isso mesmo, dimensionar a questão da violência não é simples. Identificá-la não é sempre possível, pois nem sempre deixa marcas, pode não ser reconhecida, denunciada ou registrada. Os registros mundiais variam muito de acordo com as fontes, a disponibilidade e a qualidade dos dados (Gawryszewski, Hidalgo, 2004; Villela, 2004; Krug, Dahlberg, Mercy, 2002).

A quantificação das mortes por causas violentas (denominadas na Saúde como causas externas), a despeito de revelar apenas uma parte do problema como formas da violência levadas ao seu grau extremo, permite uma aproximação da questão pela constatação da sua importância entre as diversas causas de óbito. Atualmente, no município de São Paulo, as causas externas, mais especificamente os acidentes, representam a segunda causa de óbito entre crianças de um a quatro anos e passam a ser a primeira na faixa dos cinco aos nove anos. Na adolescência, a partir dos dez anos, os acidentes são precedidos pelos homicídios, que se tornam a primeira causa de óbito (PRO-AIM, 2005).

Apesar destas evidências na mortalidade, o conhecimento da morbidade causada pela violência contra crianças e adolescentes é ainda muito limitado no nosso meio. Na literatura encontram-se dados dispersos em serviços de referência ou em projetos regionais. Segundo Azevedo e Guerra (2000), considerando-se os casos em que indivíduos adultos reconheceram ter sofrido abuso sexual na infância ou na adolescência, ou em ambas, estima-se que, na população brasileira, 20\% das mulheres e $10 \%$ dos homens tenham sido vítimas de violência sexual antes dos 18 anos.

Haveria de se considerar também as outras formas de violência intradomiciliar, onde os cuidados são distorcidos por outros abusos dos responsáveis (agressões físicas ou psíquicas), assim como as situações em que as necessidades essenciais são negadas ou negligenciadas, e, ainda, as relações onde quadros de morbidade são inventados ou mesmo induzidos pelo responsável, justificando investigações e, até mesmo, procedimentos ("Síndrome de maus-tratos por procuração" - "Munchausen").

A abordagem da violência não é simples; as dificuldades vão muito além da imprecisão do seu dimensionamento. Minayo (2000) recomenda que qualquer violência seja vista em rede: relações entre sujeitos que desempenham papéis dentro e fora do domicílio, inseridas em estruturas maiores e, não raro, também violentas. Nos serviços de saúde, o reconhecimento do risco de violência é fundamental para abrir a possibilidade de mudança.

Uma das redes importantes a ser mais bem desvelada é a que envolve a criança ou o adolescente, a família e o pediatra. Espera-se, entre várias outras coisas, que o pediatra ocupe a seguinte posição inicial na rede de atendimento: alguém que está colocado em meio às inúmeras expressões de violência que a criança ou o adolescente podem portar durante a consulta. Para tanto, a formação do residente de Pediatria deve prepará-lo para essa abordagem.

O papel que a sociedade brasileira atualmente espera que o pediatra desempenhe na rede de apoio a crianças e adolescentes sob suspeita de violência doméstica está genericamente previsto na Constituição 
Brasileira (Assembléia Nacional Constituinte, 1988), no Estatuto da Criança e do Adolescente (Brasil, 1990), no Código de Ética Médica (Brasil, 1988) e em pareceres dos Conselhos Federal (Brasil, 1999) e Regionais de Medicina (Conselho Regional de Medicina do Rio de Janeiro, 1999).

O atendimento específico às vítimas de acidentes e de violência está priorizado pela "Política Nacional de Redução de Morbimortalidade por Acidentes e Violência" (Brasil, 2001). A padronização deste atendimento foi elaborada e divulgada pela Sociedade Brasileira de Pediatria (Sociedade Brasileira de Pediatria, 2001) com o objetivo de auxiliar no reconhecimento, notificação, tratamento, seguimento, adequada referência dos casos e prevenção de reincidência ou novos episódios.

A notificação compulsória, pelo pediatra, da suspeita de maus-tratos contra crianças e adolescentes é considerada o passo inicial para a posterior intervenção de outros profissionais, para o acompanhamento da evolução dos casos e para quantificação e qualificação das expressões da violência, subsidiando ações de prevenção e de promoção próprias da Saúde Coletiva (Brasil, 2002).

Decorrentemente, este artigo tem como objetivo descrever e analisar como a VDCA está sendo apreendida e encaminhada por residentes de $2^{\circ}$ ano dos programas de residência básica de Pediatria do Município de São Paulo, Brasil.

\section{Metodologia}

Realizou-se uma pesquisa médico-social, de tipo qualitativo, que visou apreender as percepções de residentes de pediatria sobre o tema "violência doméstica contra crianças e adolescentes". Para tanto, adotou-se a perspectiva de Zizek, para quem "os fatos nunca falam por si, mas são sempre levados a falar por uma rede de mecanismos discursivos" (Zizek, 1999, p.17).

A pesquisa foi desenvolvida em duas etapas interligadas e dependentes entre si. Na primeira, foram incluídos 67 residentes do segundo ano de pediatria de nove programas de residência oferecidos no Município de São Paulo, cujos responsáveis concordaram com a realização da pesquisa. Nesta fase, os residentes foram apresentados a um "caso clínico" e depois responderam um questionário, por meio do qual deveriam ser levantadas hipóteses diagnósticas e descritos encaminhamentos, além de maiores explicações sobre o próprio caso e sobre as dificuldades do atendimento, as oportunidades de aprendizado e o papel do pediatra frente à VDCA. Os questionários foram aplicados por uma das autoras (MLMB), e todos os participantes assinaram o Termo de Consentimento Livre e Esclarecido. Com vistas a preservar a confidencialidade e o anonimato dos sujeitos da pesquisa, os nomes adotados são todos fictícios.

As respostas dos questionários foram classificadas visando tão-somente uma análise descritiva. Tal classificação permitiu a caracterização dos entrevistados e revelou tendências, em termos proporcionais, nas respostas obtidas, surgindo como pano de fundo e indicando novas questões relacionadas com a temática.

Com o objetivo de aprofundar tais questões apontadas nos questionários, na segunda etapa, foram realizadas entrevistas, como forma de transitar pelos discursos, buscando construir a compreensão das representações que tais sujeitos tinham sobre a violência.

Foram realizadas nove entrevistas em profundidade. As entrevistas foram marcadas por meio de novos contatos com os coordenadores de cada programa. O critério de seleção para as entrevistas limitou-se à disponibilidade do residente e sua anuência em se expor a esta modalidade de abordagem. O questionário anteriormente respondido serviu de roteiro para a entrevista. Foi proposto, ao residente entrevistado, que comentasse suas respostas previamente registradas. Os entrevistados usavam esse momento para repensar o que haviam escrito, explicando, ratificando, justificando, relativizando e, assim, propondo outras associações.

Ao se pensar o plano de análise, partiu-se do princípio de que os relatos obtidos dos residentes, por intermédio dos questionários e das entrevistas, expressavam conteúdos culturais, ressignificações de conteúdos históricos e sociais nos processos de subjetivação e socialização de cada um, e a possibilidade de troca no momento do preenchimento dos questionários e de interação nas entrevistas (Spink, 2000). 
As entrevistas abertas foram gravadas e, depois, transcritas. As várias leituras deste material permitiram familiaridade com o universo de respostas para cada questão e a identificação dos temas emergentes. A seguir, foram feitos recortes de cada entrevista para que as falas e os significados de cada tema pudessem ser agrupados e comparados.

Resultaram estruturas discursivas que foram reagrupadas da seguinte maneira:

- como os residentes se percebem diante da violência;

. como os residentes vêm os outros: estranhos e a criança;

- o caso clínico;

- o fazer: sobre os atendimentos e a rede;

- a formação profissional.

O projeto de pesquisa foi aprovado pelo Comitê de Ética em Pesquisa do Instituto de Saúde da Secretaria de Estado de Saúde de São Paulo.

\section{Resultados}

Os resultados se referem a 67 residentes de pediatria (formados em 31 faculdades de Medicina), inseridos em nove dos 15 programas existentes no município. Entre os entrevistados, destaca-se o predomínio de mulheres $(85 \%)$, brancas $(79 \%)$, solteiras $(64 \%)$, paulistas $(76 \%)$, católicas $(64 \%)$, com idade média de 26,6 anos.

\section{Como os residentes se percebem diante da VDCA}

Em relação às dificuldades, os residentes expressaram sentimentos e atitudes que se distribuíram em polaridades, como medo e onipotência, assim explicitados em algumas entrevistas: "E a gente já viu um caso bem evidente de maus-tratos e deixou passar por medo de intervenção dos familiares, dos amigos" (Marcelo); "Tem o medo do médico que é assim: tem muito medo do processo, de estar envolvido em questões legais ou judiciais" (Bernardo); "Olha, eu sou diferente, eu falo para os pais o seguinte: Vocês podem levar seu filho embora, mas voltam de camburão, porque a gente comunica quando tem risco pra criança. Eu falo nesse tom mesmo, que é pra eles entenderem que a gente não está de brincadeira" (Sandra).

Foi feito um paralelo entre morte e violência; os residentes as compararam, referindo que ambas são situações de extrema dificuldade na prática, e que as orientações repassadas em manuais, protocolos e aulas não bastam. Os recortes a seguir exemplificam estas associações:

Olha, é assim: no PALS (pediatrics attention life support), curso que eu fiz, eles falam como a gente deve conversar sobre algumas coisas. Recomendam que sejamos objetivos e diretos, que sejam usadas palavras comuns como morte e não óbito. E eu tive que lidar com a morte na $1^{\text {a }}$ semana, eu queria sair correndo... Só que não tem discussão sobre esse tipo de coisa: por que se faz isso com uma criança? E a gente tem que ter estrutura, só que causa muita revolta dentro da gente! É feio, muito feio! E aquilo vai acumulando dentro da gente, é muito para a minha cabeça [...] (Cecília)

Eu tenho pouca experiência. Eu acho que não sei mesmo abordar os pais. É, eu nem sei se a técnica ajudaria. De repente é mais a experiência também. É eu acho que é como lidar com a morte [...] Deveria ter apoio pra gente. É fundamental, e a gente tem que dar aporte pra eles [...] A gente é suficiente? A gente sente falta. Não é certo, pra gente ninguém dá. (Clara)

No preenchimento dos questionários, após resolverem o caso clínico, apareceram termos como "estranhamento", "negação", "rejeição", "despreparo psicológico", "angústia" e "constrangimento" como dificuldades apontadas pelos residentes diante das suspeitas de VDCA; e depois, nas entrevistas, estas dificuldades foram retomadas, evidenciando outras manifestações do medo, como pode ser visto a 
seguir: "Essas são coisas que mexem muito com a gente. Tem dias que a gente fica tão revoltada de ver bebês com fraturas e tudo mais! É difícil a gente enxergar essa mãe [...] A gente começa a ter uma repugnância da pessoa [...] é involuntário" (Cecília).

\begin{abstract}
Uma vez chegou no pronto socorro uma criança chocada por diarréia, trazida pela vizinha. Estabilizamos o quadro hemodinâmico e indicamos a internação. A vizinha foi falar com a assistente social e começou a ameaçar: - Olha, a mãe dessa criança é marginal, ela é traficante. Ela vai vir aqui com o pessoal dela, vai invadir esse pronto socorro e vamos levar essa criança embora [...] Não tinha condições de alta; a gente manteve ela lá, com medo. Com receio de entrar alguém lá à noite e metralhar a gente...mas tudo bem. (Marcelo)
\end{abstract}

\begin{abstract}
Você denuncia e fica aquele drama: polícia na casa dele; polícia, não, o Conselho Tutelar. E aqui, nós temos um bairro que é uma favela e lá fica o pai que é traficante de droga, e você manda a polícia na casa dele. Ele não tem nada pra fazer. Ele pode ficar ali o dia inteiro, esperando você sair do hospital, vendo a sua rotina, onde você mora, o carro que você tem [...] Ou seja tem um medo muito grande dos profissionais do pronto socorro que a gente também sente. (Marcelo)
\end{abstract}

Deve ser destacado que foi elevado o número de residentes que, no questionário, expressaram medo e sentimentos correlacionados, tanto do sexo feminino quanto do masculino. Entre os residentes com medo (ou sentimentos correlacionados) diante da suspeita de VDCA, a maioria reconheceu dificuldades pessoais (pré-julgamentos, angústia, constrangimento, desinteresse, negação, rejeição, estranhamento, medo do perpetrador), mais da metade citou dificuldades técnicas (como tirar a história, como diagnosticar, como romper o pacto do silêncio e as omissões), e uma minoria descreveu as famílias envolvidas nesta situação como "hostis".

Chamou a atenção o fato de que os residentes que relataram alguma forma de medo também consideraram a própria formação insuficiente, assim como a constatação de que o medo também foi citado por mais da metade daqueles que consideraram a formação suficiente.

\title{
Como os residentes vêem o outro e a criança
}

O reconhecimento de "famílias hostis" como uma das dificuldades de enfrentamento da violência apareceu nas respostas dos questionários, e muitos destes também alegaram medo. Esse estranhamento do outro pôde ser mais bem detalhado nas entrevistas. Como pode ser visto nos trechos destacados a seguir, alguns residentes descreveram os responsáveis e as famílias identificando-os como incultos, ignorantes, pobres e "barraqueiros", condições que, segundo eles, limitam o entendimento e o seguimento: "Eu acho que a mãe que não trata da higiene do próprio filho, tem que ser orientada. Porque, algumas vezes, é por ignorância e, às vezes, por falta de cultura" (Cecília); "É que tem muitos pais que cometem violência até por ignorância. Foram criados assim e acham que tem que ser assim: na borracha; é como eles falam" (Marcelo); "Chegam negando o ocorrido, sempre acabam ficando exaltados, brigando [...] fazendo barulheira, gritando pelo corredor... sempre vira uma desordem total, um barraco!" (César).

Os acompanhantes, como apresentados nos recortes anteriores, aparecem distorcidos por imagens padronizadas da violência e figuram no discurso dos residentes como "manos", "tatuados", "traficantes ou "drogados", "criminosos" ou "anormais".

A criança chegou no pronto socorro, você viu: maus-tratos. Você olha o pai: aquele monte de tatuagens de presídio. Que é aquele, como se diz, mano, mano bem formado! Tem tatuagem que é aquela aranha de baixo da mão ou de Nossa Senhora Aparecida; essas são feitas em presídio. É o próprio biótipo deles, o linguajar [...] Você viu um mano, mano você sabe o que é! Mano é também como eles se comunicam. (Marcelo) 
É que aqui a barra é pesada! A gente sabe que lida com pessoas que às vezes são do crime [...] É complicado! (Cecília)

Eu acho que no hospital regional é diferente do hospital central. Aqui no hospital central é uma clientela mista [...] Eles se sentem mais seguros e protegidos porque a maioria é de lá, é da região, e então eles são muito mais unidos. Eles têm uma esquema de segurança pessoal e pensam assim: se eu bati no meu filho, você não tem nada a ver com isso e a gente vai te matar se você duvidar ou se quiser, de alguma forma, acionar o Conselho Tutelar! (Isabel)

Por exemplo, se eu for conversar com algum pai ou mãe sob suspeita de maus-tratos, eu já vou totalmente imparcial: eu falo o mínimo possível e deixo isso a cargo do serviço social! Porque, geralmente, quem faz isso não é uma pessoa normal. Não é normal que bata no filho a esse ponto, igual a esse caso, chegando a fazer um hematoma! Aliás, em filho nenhum se bate! Nem em adulto, né? (César)

Na releitura dos questionários, a criança apareceu de forma tímida e dispersa, e apenas alguns poucos residentes embasaram os argumentos com que cercam sua prática, reconhecendo a criança enquanto sujeito de direitos.

\section{O caso clínico}

Em relação ao caso apresentado no questionário, a maioria dos residentes suspeitou de síndrome de maus-tratos e metade reconheceu devidamente a hipótese de bebê sacudido. Considerando que os encaminhamentos para o Serviço Social e para o Conselho Tutelar e Justiça se complementam, pode-se estimar que a quase totalidade dos residentes conduziria a criança presumida no caso para ser abordada além dos limites de atuação do pronto socorro.

Na discussão do caso, proposta no questionário da primeira fase, o seguimento para a criança foi lembrado por pouco mais que a metade dos residentes, mas, para a família, o seguimento foi lembrado por poucos deles. Apesar de a história ter sido exposta de forma sucinta, a preocupação com a sua melhoria quase não foi citada, e o risco à vida, inerente ao quadro de bebê sacudido, foi pouco reconhecido.

\section{O fazer, sobre os atendimentos e a rede}

Em relação à notificação da suspeita de VDCA, poucos residentes referiram dúvidas no questionário. As entrevistas mostraram que muitos programas poupam o residente desta conduta: "É sempre assim: se a gente identifica alguma coisa esquisita na anamnese ou algum dado que não bate [...] A gente não entra junto. Fica a cargo da assistente social decidir o que vai ser feito com a criança" (César); "Às vezes, a gente nem acha que tem violência. Tudo passa por eles: conversam com os pais, têm controle desses casos e vão atrás" (Cecília).

Isso pode ter influenciado o fato de apenas a metade reconhecer a notificação como atribuição do pediatra e poucos apontarem o relatório médico como uma das formas de efetivá-la. Nas entrevistas, houve as seguintes colocações: "Não, eu não ouvi falar da notificação" (César); "Eu nunca fiz uma notificação. Eu sempre pedi pro Serviço Social" (Cecília); "Na prática, não. Provavelmente deve existir um protocolo pra notificar, né?" (Clara).

As entrevistas também apontaram falta de compromisso e resistência à notificação, que é justificada por negligência ou por dificuldade de envolvimento com a Justiça e, até, por um certa "brasilidade" : "Eu já vi muitos casos em que o médico assistente diz: - Ah, deixa quieto [...] ou faz um relatório meia boca. Me desculpe, o termo é este mesmo, pois não dá subsídio nenhum pra Vara da Infância tomar atitude!" (Sandra). 
É muito moroso e a maioria dos médicos não quer se envolver. O oftalmo não quer dizer que tal lesão pode ser por maus-tratos, ele não quer se comprometer [...] O ortopedista diz: Não, mas é maus-tratos? É meio que um jogo de empurra, pra alguém assumir. Talvez muita coisa se deixe passar por negligência do próprio médico, por não querer se envolver. (Bernardo)

Por uma questão cultural, as questões legais ou as que envolvem alguma burocracia, o brasileiro não encara! Não é só por conta da violência; é em geral. Até pra fazer um atestado de óbito as pessoas têm medo! (Paula)

Entre os residentes que tinham ciência da responsabilidade da notificação, as entrevistas mostraram que restam dúvidas quanto à pertinência e a validade deste procedimento. A complexidade da violência gera dificuldade de entendimento e confusão, e o atendimento pode ser permeado por culpa, como se constatou na fala que se segue: "A gente fica pensando no que fez [...] Às vezes fica até meio culpada de ter feito! Fez o que deveria ter feito, mas mesmo assim parece estranho" (Tereza).

$\mathrm{O}$ desconhecimento de propostas de atendimento e a vivência parcial de algumas delas geram dúvidas, que puderam ser confirmadas nos depoimentos expostos na seqüência:

Eu sinto, eu tenho a sensação de que eu denunciando ou não denunciando, dá na mesma [...] e eu crio mais problema [...] Eu não acredito que se consiga uma reformulação de caráter familiar. Por exemplo, se é um pai que espanca a filha e a mãe denuncia [...] Eu não sei se o fato de você denunciar pro Conselho Tutelar vai mudar alguma coisa. Eu não vejo esta mãe se divorciando, eu vejo o Conselho Tutelar indo lá e, mesmo assim, o pai batendo na mãe porque ela o denunciou. (Isabel)

Existe também a preocupação com a grande chance da mãe perder a guarda! E se ela perder a guarda, esta criança vai pra um lugar melhor, a vida dela vai melhorar? (Paula)

É a nossa parte a gente faz. E depois? Como lidam com essas crianças? O que podem fazer de verdade? Será que valeu a pena notificar o caso? Será que valeu a pena tirar essa criança da mãe e mandar pra uma instituição onde ela corre o risco de ser agredida por outras pessoas? Será que ela não preferiria apanhar da própria mãe do que apanhar de um desconhecido, ou passar fome na casa dela do que passar fome numa instituição? (Marcelo)

Na etapa do questionário, foram escassas as referências à notificação como uma questão de direito da criança e do adolescente, enquanto a "parceria" com o serviço social na abordagem da violência foi muito citada nas entrevistas. A qualidade dessa relação é que variou. Há serviços em que ela é considerada fundamental: "O papel do assistente social é fundamental! A gente funciona como um enviador ao serviço social" (Isabel).

Em outros, é tida como rotina e, às vezes, com certo exagero, mas com a possibilidade de complementaridade: "É praxe o serviço social entrar nos casos de VDCA. Até em caso de queimadura e de intoxicação exógena o serviço social entra! Eles conversam separado e depois comentam com a gente" (Cecília); "Às vezes a gente nem acha! Tudo passa por eles e depois eles voltam, comentam e trocam idéias com a gente" (Clara).

Em outra fala, é atribuída ao serviço social uma capacidade de escuta diferenciada, assim como a responsabilidade pelo encaminhamento dos casos, do qual o residente se ausenta: "A assistente social entra pra comprovar se o ocorrido foi mesmo maus tratos. É sempre assim: a gente não entra junto, fica a cargo da assistente social decidir o que vai ser feito com a criança" (César).

Em relação à atuação do Conselho Tutelar, nas entrevistas apareceram tanto a revolta diante da condução inadequada de determinados casos quanto a discordância da proposta básica de reinclusão da criança na família: 


\begin{abstract}
Uma coisa é ler no Guia da Sociedade de Pediatria que as crianças sob suspeita de maustratos devem ser encaminhadas para o Conselho Tutelar ou pra Vara da Infância; outra coisa é ver que, na prática, as coisas não são simples assim. Foi desestimulante: tanto empenho da gente naquele caso pra, no final, o Conselho Tutelar mandar a criança de volta pra casa, dizendo que fariam visitas mensais! Deixar uma criança de oito meses, que chegou no estado que aquela menina chegou, voltar pra casa não dá pra entender. (Bernardo)
\end{abstract}

Eu fiquei bastante surpresa quando soube numa aula que o Conselho Tutelar prioriza a reinclusão da criança no próprio lar! Eu não sei se o Conselho Tutelar fica vigiando um tempo suficiente pra ter certeza de que a violência não acontecer de novo. (Isabel)

A Justiça foi reconhecida como morosa. As entrevistas também evidenciaram imagens muito negativas dos abrigos, embora somente alguns residentes tenham referido descrédito nos abrigos como dificuldade importante na tomada de decisão de notificar.

\title{
A formação profissional
}

As respostas obtidas dos questionários evidenciaram diversas oportunidades de aprendizado das questões da violência contra a criança e o adolescente reconhecidas pela maioria dos residentes durante a graduação e a residência de pediatria. Entre as oportunidades deste aprendizado, destacaram-se: a pediatria e a medicina legal como disciplinas da graduação reconhecidas, ambas, pela maioria dos residentes, seguidas pela ética e a ginecologia. Nota-se também que a residência de pediatria aumenta a oportunidade de contato com casos de violência nos diversos estágios em relação à graduação, chegando a ser apontada por quase todos os residentes no pronto socorro.

Apesar de os residentes enumerarem diversas oportunidades de contato com o tema durante a graduação e a residência, a grande maioria caracterizou a formação como insuficiente. Alguns afirmaram ter tido acesso à teoria, mas que isso não foi retido. Nas entrevistas, os residentes descreveram uma inadequação entre a teoria apresentada e as necessidades da prática.

\footnotetext{
A formação, não tanto pela violência, não entra na relação médico paciente e isto faz falta, até pra abordagem da violência, pra todos os aspectos. Você sabendo o que é uma boa relação médico paciente, tendo mais segurança pra entrar em detalhes mais complicados, você consegue lidar com a violência, com qualquer assunto, até com a morte. Até tem aula de psicologia médica, mas não se dá muito valor. Dá-se muito valor para as bulhas rítmicas, para a tomografia, para tudo o que possa ser mostrado para os outros colegas. E da relação, o que é que o outro vai saber? O instrumental que a gente traz não é satisfatório; há necessidade de mais! (Paula)
}

Na faculdade falam muita coisa, conceitos [...] Mas não adianta, não fica. Tem que ter mais, mas não assim por aula, assim é muito chato! A gente já tem que estudar tanta coisa! Não sei bem como [...] (Bernardo)

O diagnóstico da VDCA foi a atribuição do pediatra mais reconhecida pelos residentes. Poucos, todavia, referiram como atribuição também o tratamento. Com relação à prevenção da VDCA, igualmente poucos se posicionaram, e os que o fizeram disseram não estar preparados.

\section{Discussão}

Este estudo, apesar de não ter se prendido a critérios estatísticos quanto ao tamanho e à seleção da amostra, apresenta de forma inédita o residente de pediatria diante da VDCA. Não houve nenhum direcionamento para questões de gênero na inclusão dos sujeitos da pesquisa. O predomínio de 
mulheres entre os sujeitos da pesquisa confirma o predomínio de mulheres na Pediatria, relatado por Machado e Vaz (2001) na descrição do perfil dos pediatras no Brasil.

A primeira aproximação do objeto do estudo, feita por meio dos questionários, mostrou um campo carregado de ruídos e evidenciou que era necessário ampliar a escuta, dar espaço para que os residentes pudessem expressar como se sentiam, como se posicionavam diante de uma questão tão complexa.

A freqüência e a intensidade dos relatos de medo motivaram a busca de um maior entendimento, justificando uma mudança no projeto inicial da pesquisa: abdicou-se da intenção de se acessar o maior número de residentes, para se aprofundar na abordagem desta questão por intermédio de entrevistas.

O medo e os sentimentos a ele relacionados na abordagem das situações de risco de violência vêm sendo reconhecidos, por vários autores, como uma condição que permeia a atuação dos profissionais da saúde (Kiss, 2004; Bannon, Carter, 2003; Gomes et al., 2002; Gonçalves, Ferreira, 2002).

Coerentemente, este estudo confirma o medo de mais uma categoria, a dos residentes de pediatria diante da suspeita de violência.

Evidenciou-se, por meio das falas, que a suspeita ou a condição de violência complicam a relação médico-paciente, distorcendo papéis e fazendo prevalecer uma necessidade maior de defesa de ambos os lados. Segundo Ferenczi (1992), isto ocorre quando a possibilidade de entender o outro é substituída pela sua introjeção, fazendo com que este Outro desapareça enquanto realidade exterior, tornando-se intrapsíquico, gerando confusão de sentimentos e medo, que se expressam em atitudes como pactuações com o silêncio em nome de "uma estabilidade possível". O residente distorce o momento do atendimento, colocando a imagem estigmatizada do agressor em cena, predestinando esse papel ao responsável que acompanha a criança, o que determina a necessidade de se distanciar e se proteger.

É preciso resgatar o foco: o residente não é a vítima; os acompanhantes, estando ou não envolvidos com a situação de violência, não atuam o tempo todo como agressores; a criança ou o adolescente precisam de ajuda, e essa ajuda não deve ser adiada e, muito menos, se esgota numa consulta.

Neste estudo, o Outro mais reconhecido pelos residentes nas situações de suspeita de violência não é o igual em direitos, nem é a criança ou a família. É o Estranho e, como tal, ambíguo, pois, apesar de novo (desconhecido), já se apresenta preconcebido como assustador. Parece que é aí que o Outro perde a condição de Outro, e assim a condição de contraste e de distinção se mistura com algo que já tem um sentido negativo, carregado de repulsa e aflição (Freud, 1979).

As entrevistas mostraram que este Outro é o que ameaça o residente. É o diferente, mas, a um só tempo, é o igual por referência a um padrão de qualidade dos moradores da periferia, que os próprios residentes, nas entrevistas, denominaram como: incultos, pobres, anormais, traficantes, criminosos (tão explorados e indiciados na mídia da violência).

Embora não houvesse, no questionário, perguntas específicas sobre a criança, é dela que se trata: residentes estão sendo treinados para entendê-la e atendê-la. Ela deveria ser o "outro principal". A criança e o adolescente pouco se destacaram e, nos discursos, aparecem como indefesos ou ocultados pelas lesões que os maus-tratos podem causar. A sua identificação enquanto sujeitos em desenvolvimento e implicados no ciclo da violência foi rara.

Há que se pensar também na posição que crianças e adolescentes ocupam na sociedade brasileira. Neste sentido, Del Priore (2004) reuniu historiadores, sociólogos e outros especialistas para abordar a condição da infância no Brasil, pensando a situação atual como um legado da história que vem sendo construído e incorporado à condição de ser criança numa sociedade injusta na distribuição de suas riquezas, avara quanto ao acesso à educação e marcada pelo escravismo.

A apresentação de um caso clínico foi válida, pois permitiu uma introdução ao tema por meio de situações já experimentadas, condição muito presente na argumentação dos residentes incluídos neste estudo. O aparente êxito, diante das hipóteses e encaminhamentos apontados para o caso apresentado, deve ser relativizado pois, na realidade, não traduz suficiência dos residentes diante da VDCA.

Este estudo não se estendeu na análise das formas como a VDCA é abordada na graduação nem nos programas de residência de pediatria; apenas se aproximou do que resulta desta abordagem, por intermédio dos discursos (relatos) dos residentes. A princípio parece haver, por parte dos aparelhos formadores, preocupação com o tema e, a um só tempo, necessidade de conhecimento, uma vez que a maioria dos sujeitos da pesquisa reconheceu várias oportunidades de aprendizado em disciplinas da 
graduação e quase a totalidade citou contato com casos sob suspeita de violência nos estágios de Pronto Socorro da residência. Todavia, tanto o descontentamento em relação à suficiência deste aprendizado, assumido pela maioria dos residentes, quanto a escassez das atribuições do pediatra diante da VDCA, reconhecidas por eles, apontam para algo não esgotado. O medo não reconhecido (ou desconhecido) por parte dos formadores, e tão prevalente entre os sujeitos desta pesquisa, evidenciou-se como um possível bloqueador do aprendizado e, conseqüentemente, do desempenho que deve ser trabalhado para que se experimentem novos resultados.

\section{Considerações finais}

Os resultados desta pesquisa confirmaram dificuldades inerentes ao tema violência e a importância de repensá-la na formação dos residentes.

O estudo permitiu uma aproximação da realidade, partindo do princípio de que "a realidade nunca é diretamente ela mesma, pois só se apresenta através de sua simbolização" (Zizek, 1999, p.26), e de que a prática resulta de uma ideologia que é concreta, justifica e gera ações (Althusser, 1999).

Essencialmente, o que se pode concluir é que o "bebê sacudido", imagem clássica de VDCA, tem sido freqüentemente exposto aos residentes. A proposta de seguimento ambulatorial parece remota, uma vez que não foi referida espontaneamente entre as condutas listadas, só sendo lembrada por, aproximadamente, metade dos residentes quando estimulados a pensar nesta possibilidade. Nenhum residente levantou a possibilidade de seguimento ou tratamento para o perpetrador.

Os resultados das entrevistas também evidenciaram que as estruturas dos programas não comportam ou não priorizam o atendimento ambulatorial e, menos ainda, o seguimento dos casos sob suspeita de violência, o que implica uma abordagem incompleta e resulta como um limite da formação.

Chamou a atenção o fato de os residentes enumerarem diversas oportunidades de contato com o tema durante a graduação e a residência, e a grande maioria ter caracterizado a formação como insuficiente. Vários autores, como Middleman, Binns e Durant (1995), Borowsky e Ireland (1999), Jonhson et al. (1999), Bair-Merritt et al. (2004), vêm se ocupando do papel do pediatra como triador de comportamentos de risco para a violência.

Estes estudos mostram que a dificuldade do ensino das questões da VDCA é comum, e que o fato de haver protocolos e novas propostas não tem garantido um maior compromisso do pediatra. Há mais conhecimento para ser reconhecido e desvendado.

Muitas questões precisam ser retomadas e melhoradas na formação dos residentes e, dentre elas, destaca-se a busca dos motivos do medo, que foi evidenciado como impedimento, limitando a possibilidade de se reconhecer a criança ou o adolescente em sua alteridade. Esboçaram-se explicações que ainda devem ser melhor aferidas.

A rotina e a demanda se entrelaçam, borram os contornos do fazer, que é, sem dúvida, efetivado por sujeitos, em parte, conscientes e carregados de ideologias. Redefinir o fazer, escutando os que fazem, aceitando que tudo com o que lidamos são também produtos simbólicos, foi um exercício que resultou numa aproximação maior com as idéias que orientam a prática pediátrica, restando o desafio de rever ideologias e sistemas de crenças de quem está se propondo a formar e as dos que estão se sujeitando (ou não) ao que vem sendo proposto.

\section{Colaboradores}

Maria Lúcia de Moraes Bourroul foi responsável pela redação e revisão do artigo. As discussões e revisões foram feitas por todos os autores. 


\section{Referências}

ALTHUSSER, L. Ideologia e aparelhos ideológicos do Estado. In: ZYZEK S. O mapa da ideologia. São Paulo: Contraponto, 1999. p.105-42.

ASSEMBLÉIA NACIONAL CONSTITUINTE. Constituição da República Federativa do Brasil - 1988. Disponível em: <http://www.senado.gov.br>. Acesso em: 22 out. 2008.

AZEVEDO, M.A.; GUERRA, V.N.A. (Orgs.). Infância e violência doméstica: fronteiras do conhecimento. 3.ed. São Paulo: Cortez, 2000.

BAIR-MERRITT, M.H. et al. Pediatric residency training on domestic violence: a national survey. Ambul. Pediatr., v.4, n.1, p.24-7, 2004.

BANNON, M.J.; CARTER, Y.H. Pediatrician and child protection: the need of effective education and training. Arch. Dis. Child., n.88, p.560-2, 2003.

BOROWSKY, I.W.; IRELAND, M. National survey of pediatricians' violence prevention counseling. Arch. Pediatr. Adolesc. Med., n.153, p.1170-6, 1999.

BOURROUL, M.L.M. A violência doméstica contra a criança e o adolescente e o ensino de Pediatria na residência médica. 2005. Dissertação (Mestrado) - Programa de Pós-Graduação, Coordenadoria de Controle de Doenças, Secretaria de Estado da Saúde de São Paulo, São Paulo. 2005.

BRASIL. Ministério da Saúde. Notificação de maus-tratos contra crianças e adolescentes pelo profissional de saúde. Brasília: Secretaria de Assistência à Saúde, 2002. (Manual Técnico do Ministério da Saúde, 167).

Ministério da Saúde. Portaria n.737, de 6 de maio de 2001. Política Nacional de Redução de Morbimortalidade por Acidentes e Violência Brasília: Ministério da Saúde, 2001.

Conselho Federal de Medicina. Código de Ética Médica. Resolução no 1246/ 1988 e Resolução no 13/1999. Disponível em: <http://www. portalmédico.org.br>. Acesso em: 22 out. 2008.

Lei n 80691/1990. Estatuto da Criança e do Adolescente. Diário Oficial da União, Brasília, DF, 16 e 27 jul. 1990.

CONSELHO REGIONAL DE MEDICINA DO RIO DE JANEIRO. Parecer n.76/99.

Disponível em: <http://www. portalmédico.org.br>. Acesso em: 22 out. 2008.

DEL PRIORE, M. História das crianças no Brasil. São Paulo: Contexto, 2004.

FERENCZI, S. Obras completas - Psicanálise. São Paulo: Martins Fontes, 1992.

FREUD, S. O estranho. In:___ Obras psicológicas completas de Sigmund Freud. Rio de Janeiro: Imago, 1979. v.22. p.275-314.

GAWRYSZEWSKI, V.P.; HIDALGO, N. Vigilância epidemiológica não é só para doenças infecciosas: a proposta do estado de São Paulo para os acidentes e formas de violência. Bol. Inst. Saúde, n.33, p.13-5, 2004.

GOMES, R. et al. A abordagem dos maus-tratos contra a criança e o adolescente em uma unidade pública de saúde. Ciênc. Saúde Coletiva.,v.7, n.2, p.275-83, 2002.

GONÇALVES, H.S.; FERREIRA, A.L. A notificação da violência intrafamiliar contra crianças e adolescentes por profissionais de saúde. Cad. Saúde Pública, v.18, n.1, p.315-9, 2002.

JOHNSON, C.D. et al. Violence prevention in the primary care center. Arch. Pediatr. Adolesc. Med., n.153, p.531-5, 1999. 
KISS, L.B. Temas médico-sociais e a intervenção em saúde: a violência contra mulheres no discurso dos profissionais. 2004. Dissertação (Mestrado) - Departamento de Medicina Preventiva, Faculdade de Medicina, Universidade de São Paulo, São Paulo. 2004

KRUG, E.G.; DAHLBERG, L.L.; MERCY, J.A. Relatório mundial sobre violência. Genebra: OMS, 2002.

MACHADO, M.H; VAZ, E.S. Perfil dos pediatras no Brasil: relatório final. Rio de Janeiro: Sociedade Brasileira de Pediatria, 2001.

MIDDLEMAN, A.B.; BINNS, H.J.; DURANT, R.H. Factors affecting pediatric residents' intentions to screen for high risk behaviors. J. Adolesc. Health., v.17, n.2, p.106-12, 1995.

MINAYO, M.C.S. Violência contra crianças e adolescentes: questão social, questão da saúde. Rev. Bras. Saúde Mater.-Infant., v.1, n.2, p.91-102, 2000.

PRO-AIM. Programa de Aprimoramento de Informações de Mortalidade. CEINFO Centro de Informação e Epidemiologia. Secretaria Municipal da Saúde de São Paulo. Disponíveis em: <http://www.prefeitura.sp.gov.br/secretarias/saúde. Acesso em: 22 out. 2008.

SOCIEDADE BRASILEIRA DE PEDIATRIA. Guia de atuação frente a maus- tratos na infância e na adolescência. 2.ed. Rio de Janeiro: Ministério da Justiça, 2001.

SPINK, M.J.P. Práticas discursivas e produção de sentidos no cotidiano. 2.ed. São Paulo: Cortez, 2000.

VILLELA, W.V. O que é a violência, afinal, para cada um de nós? Bol. Inst. Saúde, n.33, p.11-2, 2004.

VILLELA, W.V.; BOTAZZO, C. Refletindo sobre os nexos entre violência e saúde. Bol. Inst. Saúde, n.33, p.5-7, 2004.

ZIZEK, S. O espectro da ideologia. In: O mapa da ideologia. São Paulo:

Contraponto, 1999. p.7-38.

BOURROUL, M.L.M.; REA, M.F.; BOTAZZO, C. Residentes de pediatría ante la violencia doméstica contra niños y adolescentes. Interface - Comunic., Saúde, Educ., v.12, n.27, p.737-48, out./dez. 2008.

Este artículo trata de las percepciones de residentes de pediatría ante la violencia doméstica contra niños y adolescentes. Se ha realizado un estudio cualitativo con 67 residentes ubicados en nueve de los 15 programas existentes en el municipio de São Paulo, Brasil, con cuestionarios semi-estructurados y entrevistas en profundidad con nueve sujetos. Casi todos expresaron miedo y caracterizaron la formación como insuficiente. Las declaraciones sugieren disciriminación y extrañamiento delate del otro, caracterizando una situación en que sociedades diferentes aparecen como amenazadoras. Diagnosticar violencia es la atribución del pediatria más reconocida. Hay etapas del atendimiento de los niños con riesgo de violencia a ser mejor entendidas. Aspectos del residente, como el miedo, han de ser considerados para que pueda reconocer al niño en su alteridad y ejecutar mejor su papel.

Palabras clave: Malos tratos infantiles. Etica médica. Educación médica. Residencia médica. Violencia doméstica. 